\title{
Modern Prospection for Hepatic Arterial Infusion Chemotherapy in Malignancies with Liver Metastases
}

\author{
Yi-Hsin Liang, ${ }^{1,2}$ Yu-Yun Shao, ${ }^{2,3}$ Jia-Yi Chen, ${ }^{2}$ Po-Chin Liang, ${ }^{4}$ \\ Ann-Lii Cheng, ${ }^{2,3,5}$ and Zhong-Zhe Lin ${ }^{2,5}$ \\ ${ }^{1}$ Department of Hemato-Oncology, E-Da Hospital, No. 1, Yi-da Road, Jiaosu Village, Yanchao, Kaohsiung 82445, Taiwan \\ ${ }^{2}$ Department of Oncology, National Taiwan University Hospital, No. 7, Chung-Shan South Road, Taipei City 10002, Taiwan \\ ${ }^{3}$ Graduate Institute of Oncology, College of Medicine, National Taiwan University, No. 1, Section 1, Ren-Ai Road, \\ Taipei City 10051, Taiwan \\ ${ }^{4}$ Department of Medical Imaging, National Taiwan University Hospital, No. 7, Chung-Shan South Road, Taipei City 10002, Taiwan \\ ${ }^{5}$ Department of Internal Medicine, National Taiwan University Hospital, No. 7, Chung-Shan South Road, Taipei City 10002, Taiwan
}

Correspondence should be addressed to Zhong-Zhe Lin; zzlin7460@ntu.edu.tw

Received 28 December 2012; Revised 6 March 2013; Accepted 25 March 2013

Academic Editor: Jorge Ortiz

Copyright (C) 2013 Yi-Hsin Liang et al. This is an open access article distributed under the Creative Commons Attribution License, which permits unrestricted use, distribution, and reproduction in any medium, provided the original work is properly cited.

Malignancy with liver metastasis plays an important role in daily oncology practice, especially for primary cancers of the gastrointestinal tract and hepatopancreatobiliary system. On account of the dual vascular supply system and the fact that most metastatic liver tumors are supplied by the hepatic artery, hepatic artery infusion chemotherapy (HAIC) is an appealing method for the treatment of liver metastases. Herein, we summarize recent study results reported in the literature regarding the use of HAIC for metastatic liver tumors, with special focus on colorectal cancer.

\section{Introduction}

Malignancy with liver metastasis plays an important role in daily oncology practice, especially for primary cancers of the gastrointestinal (GI) tract and hepatopancreatobiliary system [1]. The liver is commonly the first site of distant metastasis. For example, about three-quarters of patients with stage IV colorectal cancer (CRC) have liver metastases [2]. Many of these patients have metastatic disease confined to the liver only. It has been demonstrated that for patients with such limited distant metastases, locoregional therapy such as surgery may be helpful $[3,4]$. However, usually the liver metastases are too advanced to be resected by hepatectomy. Fewer than $15 \%$ of these patients receive hepatectomy to a curative extent [5].

On account of the dual vascular supply system and the fact that most metastatic liver tumors are supplied by the hepatic artery [6, 7], hepatic artery infusion chemotherapy (HAIC) is an appealing method for the treatment of liver metastases. HAIC has several advantages over intravenous chemotherapy. First, chemotherapeutic agents can be delivered more specifically to malignant cells. Normal hepatocytes that mostly rely on the portal venous system are thus exposed to fewer chemotherapeutic agents. Second, many chemotherapy agents used in HAIC have a high firstpass hepatic clearance effect, such as 5-fluorouracil (5-FU) and floxuridine (FUDR), a prodrug of 5-FU. Over $90 \%$ of FUDR and $19 \%-50 \%$ of 5 -FU are cleared by the liver when they are administered by HAIC [8]. Systemic exposure to chemotherapeutic agents is thus decreased.

These two mechanisms enable HAIC to provide a higher exposure of chemotherapy to malignant cells with minimized toxicities. The higher drug level may also overcome drug resistance. For example, intravenous (IV) anthracyclines are generally considered ineffective for CRC. HAIC with pirarubicin, an anthracycline that is an analogue of doxorubicin, has been demonstrated to have a fair efficacy in CRC patients with liver metastases [9-11]. 
The equipment and skills related to HAIC have been in development for more than 5 decades. With advances in implantable catheters and ports, external infusion pumps can be avoided to decrease catheter-related complications. Catheter implantation is generally performed via the femoral, axillary, or subclavian arteries under fluoroscopic guidance [12-15]. The angiography should be carefully reviewed before and after catheter implantation to identify any anomalous vasculature. The tips of HAIC catheters are fixed at the gastroduodenal artery or proper hepatic artery. The HAIC ports are then immobilized subcutaneously. Finally, a perfusion scan is usually performed for HAIC catheters to detect any unexpected shunting to other organs.

Adverse reactions to HAIC can be divided into catheterrelated complications and chemotherapy-related complications. Common catheter-related complications include catheter displacement, hepatic artery occlusion, and catheterrelated infection [16-18]. The complication rates for these issues have been reported to be lower than $7 \%$ in recent studies, compared to $22-35 \%$ in earlier studies. The most common chemotherapy-related complication is gastrointestinal symptoms. Nausea and vomiting can occur in 25-35\% patients $[17,19]$. Hepatobiliary toxicity, including elevation of serum hepatic transaminase levels, and hyperbilirubinemia are also important problems [20-23].

Although the rationale for the use of HAIC for metastatic liver tumors is appealing, the actual benefit of HAIC is not wholly clear. The lack of large randomized clinical trials makes it difficult to examine the overall survival benefits. However, results from previous studies are accumulating gradually and could provide some hints as to the actual efficacy of HAIC for metastatic liver tumors. Herein, we summarize recent study results reported in the literature with regards to the use of HAIC for metastatic liver tumors, with special focus on CRC.

\section{Colorectal Cancer}

2.1. HAIC Combined with Systemic Chemotherapy. CRC is the third most prevalent malignant disease around the world $[24,25]$. Despite screening and early surgery, many patients eventually suffer from metastatic disease. The liver is the most frequent metastatic site of CRC. CRC with liver metastasis becomes an important issue for treatment of metastatic CRC, and HAIC potentially provides good local control with a response rate (RR) ranging from $34 \%$ to $92 \%$ (Table 1) when combined with systemic chemotherapy.

Mancini et al. conducted a clinical trial that enrolled 123 CRC patients with unresectable liver metastasis [27]. The patients were randomized into two arms. In arm one, patients received intravenous 5-FU chemotherapy and infusional cisplatin via HAIC. In arm two, patients received intravenous 5-FU chemotherapy and bolus cisplatin via HAIC. There was no significant difference in response between the two arms, and thus, treatment response was presented as a combination of all patients in the two arms. The overall RR was 52\%, which included a $17 \%$ complete response rate. The median overall survival (OS) was 18 months and 28 months for all patients and responders, respectively. Kemeny et al. conducted a clinical trial that enrolled 49 patients with CRC who had unresectable liver-confined metastasis only [31]. The patients received intravenous oxaliplatin and irinotecan (CPT-11) combined with FUDR via HAIC. The overall RR was $92 \%$, which included a $8 \%$ complete response rate [31]. The median OS was 50.8 months for chemotherapy-naive patients and 35 months for previously-treated patients.

Although these studies did not incorporate targeted therapy agents, the reported response rates are comparable to current standards using combination therapy with targeted and cytotoxic chemotherapy. However, whether the addition of HAIC to current standard treatment, which generally provides a high response rate of $47 \%-64 \%$, is useful remains unclear [32-35]. Recently, targeted therapy has also been used with HAIC in some small series. Bouchahda et al. demonstrated that HAIC could be combined with intravenous cetuximab in two patients in a retrospective study [36]. Further research with different combinations of novel targeted therapy is warranted.

2.2. Reversing Inoperable Disease to Operable Disease. For patients with CRC and liver-only metastatic disease, complete resection provides the chance of a cure. When liver metastatic disease develops, complete resection can provide a potential cure for CRC patients. However, only $10-15 \%$ of these patients are eligible for such surgery upon diagnosis [5]. Because of the high response rate, HAIC may reverse inoperable liver metastatic disease to an operable status.

Kemeny et al. conducted a clinical trial examining the use of intravenous oxaliplatin and CPT-11 combined with FUDR via HAIC for patients with CRC-related unresectable liver-confined metastasis only [31]. Initially, 98\% of these resectable cases had bilobar metastatic lesions, and $73 \%$ of them had $>5$ hepatic lesions. The overall RR was high at 92\%. Twenty-three (47\%) patients eventually received hepatectomy to a curative extent. Yamaguchi et al. conducted a clinical trial that enrolled 22 patients who had CRC and unresectable liver metastasis to receive intravenous CPT-11 with oral tegafur/uracil in combination with 5 -FU via HAIC [26]. The definition of unresectability included (1) tumors involved all liver segments, (2) inadequate liver reservation after resection, and (3) tumors involved all main hepatic veins or both inflow pedicles. The overall RR was $86.4 \%$, and eventually 14 patients (63.6\%) underwent complete resection of liver tumors.

Other than 5-FU, oxaliplatin and CPT-11 have also been tested in HAIC. Ducreux et al. conducted a clinical trial that enrolled 28 patients who had CRC-related inoperable liverconfined metastatic diseases only [37]. Twenty-one of these patients had received previous intravenous 5-FU therapy. The patients then received intravenous 5-FU and leucovorin (LV) with oxaliplatin infused via HAIC. The RR was $64 \%$, and the median overall survival (OS) was 27 months. Approximately $18 \%$ of patients' diseases became operable following therapy. The same group then further applied this regimen in a second-line setting [38]. Boige et al. conducted a clinical trial that enrolled 44 patients who had CRC-related inoperable 
TABLE 1: Selective studies of combining HAIC with systemic chemotherapy for colorectal cancer.

\begin{tabular}{|c|c|c|c|c|c|c|c|c|c|}
\hline Authors & Year & Setting & Treatment & Line & $\begin{array}{l}\text { Inclusion } \\
\text { population }\end{array}$ & $\begin{array}{c}\text { Patient } \\
\text { no. } \\
\left(\text { treat }^{\mathrm{a}}\right)\end{array}$ & $\begin{array}{c}\text { Median } \\
\text { OS } \\
\text { (months) }\end{array}$ & $\mathrm{RR}$ & Note \\
\hline $\begin{array}{l}\text { Yamaguchi et al. } \\
\text { [26] }\end{array}$ & 2011 & $\begin{array}{c}\text { Pro, } \\
\text { phase I/II }\end{array}$ & $\begin{array}{c}\text { HAIC } \rightarrow 5-\mathrm{FU} \\
\mathrm{IV} \rightarrow \mathrm{CPT}-11+\mathrm{LV} \\
\text { Oral tegafur/uracil }\end{array}$ & First line & $\begin{array}{l}\text { Unresectable } \\
\text { hepatic mets }\end{array}$ & $\begin{array}{l}\text { Phase 1: } \\
12(12) \\
\text { Phase 2: } \\
22(22)\end{array}$ & Not reach & $86.4 \%$ & $\begin{array}{l}\text { RCR: } \\
63.6 \%\end{array}$ \\
\hline
\end{tabular}

\begin{tabular}{|c|c|c|c|c|c|c|c|c|c|}
\hline $\begin{array}{l}\text { Mancini et al. } \\
\text { [27] }\end{array}$ & 2003 & Pro, Ran & $\begin{array}{c}\text { Arml: HAIC } \rightarrow \text { continuous } \\
\text { cisplatin } \\
\text { IV } \rightarrow 5 \text {-FU } \\
\text { Arm } 2: \text { HAIC } \rightarrow \text { bolus } \\
\text { cisplatin } \\
\text { IV } \rightarrow 5 \text {-FU }\end{array}$ & First line & $\begin{array}{l}\text { Unresectable } \\
\text { hepatic mets }\end{array}$ & $\begin{array}{l}58(58) \\
65(65)\end{array}$ & 18 & $52 \%$ & \\
\hline Goéré et al. [28] & 2010 & Ret & $\begin{array}{l}\text { HAIC } \rightarrow \text { oxaliplatin } \\
\quad \mathrm{IV} \rightarrow 5 \text {-FU }+\mathrm{LV}\end{array}$ & $\begin{array}{l}\text { First line: } 18 \\
\text { Second line: } 69\end{array}$ & $\begin{array}{l}\text { Unresectable } \\
\text { hepatic mets }\end{array}$ & $87(87)$ & NM & $55 \%$ & $\begin{array}{l}5 \text {-year } \\
\text { sur- } \\
\text { vival: } \\
56 \%\end{array}$ \\
\hline $\begin{array}{l}\text { Gallagher et al. } \\
{[29]}\end{array}$ & 2007 & Ret & $\begin{array}{c}\text { HAIC } \rightarrow \text { FUDR + Dexa } \\
\text { IV } \rightarrow \text { CPT-11 }\end{array}$ & $\begin{array}{c}\text { Failed } \\
\text { oxaliplatin }\end{array}$ & $\begin{array}{l}\text { Unresectable } \\
\text { hepatic mets }\end{array}$ & $39(39)$ & 18 & $44 \%$ & \\
\hline $\begin{array}{l}\text { Pilati et al. } \\
{[30]}\end{array}$ & 2009 & Ret & $\begin{array}{c}\text { Arm1: HAIC } \rightarrow \text { FUDR + LV } \\
\text { Arm2: HAIC } \rightarrow \text { FUDR + LV } \\
\text { IV } \rightarrow 5-\mathrm{FU}+\text { LV }\end{array}$ & NM & $\begin{array}{l}\text { Unresectable } \\
\text { hepatic mets }\end{array}$ & $\begin{array}{l}72(72) \\
81(81)\end{array}$ & $\begin{array}{c}18 \\
19.1\end{array}$ & $\begin{array}{l}52.7 \% \\
50.6 \%\end{array}$ & \\
\hline
\end{tabular}

Selected studies that enroll patients with colorectal cancer to receive systemic chemotherapy in combination with HAIC are listed here. Studies designed for patients with colorectal cancer-related liver-confined metastatic disease were listed in Table 2.

${ }^{*}$ With statistical significance.

${ }^{a}$ Actual patients' number who received treatment.

Abbreviations-OS: overall survival, RR: response rate, Pro: prospective, Ran: randomized, Ret: retrospective, NM: not mentioned, HAIC: hepatic artery infusion chemotherapy, IV: intravenous, FUDR: floxuridine, LV: leucovorin, Dexa: dexamethasone, CPT-11: irinotecan, Mets: metastasis, and RCR: resectability conversion rate.

liver-confined metastatic diseases only and in whom first-line chemotherapy failed [38]. Treatment of twenty-eight of these patients with 5-FU, oxaliplatin, and CPT-11 had previously failed. For only one patient, 5-FU alone failed, and in the others both 5-FU and either CPT-11 or oxaliplatin treatment failed. The RR was $62 \%$ and the median overall survival (OS) was 16 months. Similarly, $18 \%$ of patients' disease became operable following therapy.

For HAIC, the hepatic resectability conversion rate is worthy of emphasis. The current standard treatment, combined targeted and cytotoxic chemotherapy, usually generates a less than $10 \%$ hepatic resectability conversion rate according to post hoc analysis [32, 35, 39]. Folprecht et al. conducted the CELIM study that enrolled 114 patients who had CRC and inoperable liver-confined metastatic diseases who received intravenous cetuximab and combination cytotoxic chemotherapy [40]. Overall, 38\% of patients eventually received curative hepatectomy. It is worthy of note that $32 \%$ of patients with paired images before and after surgery in CELIM trial were considered operable prior to chemotherapy when the images were reviewed centrally. Although there has been no large-scale phase III trial to prove the concept that HAIC might improve the liver resectability conversion rate, the above results are promising, with high response rates and good conversion rates of reversing inoperable disease to operable disease. The outcome is even more encouraging considering that these studies did not incorporate novel targeted agents, such as bevacizumab and cetuximab.
2.3. Liver-Confined Disease. Some patients who receive local therapy for early CRC may suffer from recurrence, with liver metastasis as the only disease site (liver-confined disease). Although systemic chemotherapy is the standard treatment for metastatic CRC, some of these patients had had their primary cancer treated previously and suffered from liverconfined metastatic disease. For these patients, it is reasonable to develop a local therapy with an enhanced efficacy against liver metastases. The mechanism of HAIC suits this purpose.

HAIC exhibits a high RR, ranging from $22 \%$ to $92 \%$, albeit with an unclear effect on overall survival in this setting (Table 2). In the CALGB 9481 trial, 135 CRC patients with inoperable liver-confined disease were randomly assigned to receive FUDR via HAIC or intravenous bolus 5-FU and LV [41]. Patients who received HAIC compared to patients who received IV chemotherapy had a significantly higher RR (47\% versus $24 \%, P=0.012$ ) and a longer median OS (24.4 months versus 20.0 months; $P=0.003$ ). Patients treated with HAIC had a significantly longer time to hepatic progression compared to patients who received IV chemotherapy (9.8 months versus 7.3 months; $P=0.034$ ), but a significantly shorter time to extrahepatic progression (7.7 months versus 14.8 months; $P=0.029$ ).

Besides FUDR or 5-FU, mitomycin-C (Mit-C) has also been used in HAIC $[47,49]$. Kemeny et al. randomly assigned 63 CRC patients with inoperable liver-confined disease to receive high-dose Mit-C and FUDR/LV via HAIC [47]. 
TABLE 2: Selective studies of HAIC for liver-confined metastatic disease from colorectal cancer.

\begin{tabular}{|c|c|c|c|c|c|c|c|c|}
\hline $\begin{array}{l}\text { Authors/ } \\
\text { Year }\end{array}$ & Setting & Treatment & Line & $\begin{array}{l}\text { Inclusion } \\
\text { population }\end{array}$ & $\begin{array}{l}\text { Patient no. } \\
\quad(\text { treat })^{\mathrm{a}}\end{array}$ & $\begin{array}{l}\text { Median } \\
\text { OS } \\
\text { (months) }\end{array}$ & $\mathrm{RR}$ & Note \\
\hline $\begin{array}{l}\text { Kemeny } \\
\text { et al. } \\
2006 \\
{[41]}\end{array}$ & Pro, Ran & $\begin{array}{c}\text { Arm1: HAIC } \rightarrow \text { FUDR + LV + Dexa } \\
\text { Arm2: IV } \rightarrow \text { 5-FU + LV }\end{array}$ & First line & $\begin{array}{l}\text { Unresectable } \\
\text { liver confined }\end{array}$ & $\begin{array}{l}68(59) \\
67(58)\end{array}$ & $\begin{array}{r}24.4^{*} \\
20\end{array}$ & $\begin{array}{c}47 \%{ }^{*} \\
24 \%\end{array}$ & $\begin{array}{l}\text { QOL } \\
\text { improvement }\end{array}$ \\
\hline $\begin{array}{l}\text { Fiorentini } \\
\text { et al. } \\
2006 \\
{[42]}\end{array}$ & $\begin{array}{l}\text { Pro, } \\
\text { phase III }\end{array}$ & $\begin{array}{c}\text { Arm1: HAIC } \rightarrow 5-\mathrm{FU}+\mathrm{LV} \\
\text { Arm2: HAIC } \rightarrow 5-\mathrm{FU}+\mathrm{LV} \\
\mathrm{IV} \rightarrow 5-\mathrm{FU}+\mathrm{LV}\end{array}$ & First line & $\begin{array}{l}\text { Unresectable } \\
\text { liver confined }\end{array}$ & $\begin{array}{l}40(36) \\
42(40)\end{array}$ & $\begin{array}{l}14 \\
20\end{array}$ & $\begin{array}{l}41.7 \% \\
47.5 \%\end{array}$ & \\
\hline $\begin{array}{l}\text { Fallik } \\
\text { et al. } \\
2003 \\
{[11]} \\
\end{array}$ & $\begin{array}{l}\text { Pro, } \\
\text { phase II }\end{array}$ & $\begin{array}{l}\mathrm{HAIC} \rightarrow \text { pirarubicin } \\
\quad \mathrm{IV} \rightarrow 5-\mathrm{FU}+\mathrm{LV}\end{array}$ & First line & $\begin{array}{l}\text { Unresectable } \\
\text { liver confined }\end{array}$ & 75 (69) & 20 & $34.4 \%$ & \\
\hline $\begin{array}{l}\text { Kerr } \\
\text { et al. } \\
2003 \\
{[43]}\end{array}$ & Pro, Ran & $\begin{array}{l}\text { Arm1: } \mathrm{HAIC} \rightarrow 5-\mathrm{FU}+\mathrm{LV} \\
\text { Arm } 2: \mathrm{IV} \rightarrow 5-\mathrm{FU}+\mathrm{LV}\end{array}$ & First line & $\begin{array}{l}\text { Unresectable } \\
\text { liver confined }\end{array}$ & $\begin{array}{l}145(95) \\
145(126)\end{array}$ & $\begin{array}{l}14.7 \\
14.8\end{array}$ & $\begin{array}{l}22 \% \\
19 \%\end{array}$ & \\
\hline $\begin{array}{l}\text { Allen- } \\
\text { Mersh } \\
\text { et al. } \\
2000 \\
{[44]}\end{array}$ & Pro, Ran & $\begin{array}{c}\text { Arm1: } \mathrm{HAIC} \rightarrow \text { FUDR } \\
\text { IV } \rightarrow 5-\mathrm{FU}+\mathrm{LV} \\
\text { Arm2: IV } \rightarrow 5-\mathrm{FU}\end{array}$ & First line & $\begin{array}{l}\text { Unresectable } \\
\text { liver confined }\end{array}$ & $\begin{array}{l}41(39) \\
43(42)\end{array}$ & NM & $\begin{array}{l}45 \% \\
23 \%\end{array}$ & $\begin{array}{l}\text { No QOL } \\
\text { difference }\end{array}$ \\
\hline $\begin{array}{l}\text { Lorenz } \\
\text { et al. } \\
2000 \\
{[45]}\end{array}$ & Pro, Ran & $\begin{array}{c}\text { Arm1: HAIC } \rightarrow \text { 5-FU + LV } \\
\text { Arm2: IV } \rightarrow \text {-FU + LV } \\
\text { Arm3: HAIC } \rightarrow \text { FUDR }\end{array}$ & First line & $\begin{array}{l}\text { Unresectable } \\
\text { liver confined }\end{array}$ & $\begin{array}{l}57(40) \\
57(71)^{b} \\
54(37)\end{array}$ & $\begin{array}{l}18.7 \\
17.6 \\
12.7\end{array}$ & $\begin{array}{c}45 \% \\
19.7 \% \\
43.2 \%\end{array}$ & \\
\hline $\begin{array}{l}\text { Kemeny } \\
\text { et al. } \\
2009 \\
{[31]}\end{array}$ & $\begin{array}{l}\text { Pro, } \\
\text { phase I }\end{array}$ & $\begin{array}{l}\text { HAIC } \rightarrow \text { FUDR + Dexa } \\
\text { IV } \rightarrow \text { oxaliplatin + CPT-11 }\end{array}$ & $\begin{array}{l}\text { First } \\
\text { line: } 23 \\
\text { Second } \\
\text { line: } 26 \\
\end{array}$ & $\begin{array}{l}\text { Unresectable } \\
\text { liver confined }\end{array}$ & 49 (49) & $\begin{array}{l}\text { First line: } \\
50.8 \\
\text { Second } \\
\text { line: } 35\end{array}$ & $92 \%$ & RCR: $47 \%$ \\
\hline $\begin{array}{l}\text { Ducreux } \\
\text { et al. } \\
2005 \\
{[37]} \\
\end{array}$ & Pro & $\begin{array}{l}\text { HAIC } \rightarrow \text { Oxaliplatin } \\
\quad \mathrm{IV} \rightarrow 5-\mathrm{FU}+\mathrm{LV}\end{array}$ & $\begin{array}{l}\text { First } \\
\text { line: } 7 \\
\text { Second } \\
\text { line: } 21\end{array}$ & $\begin{array}{l}\text { Unresectable } \\
\text { liver confined }\end{array}$ & $28(26)$ & 27 & $64 \%$ & RCR: 18\% \\
\hline $\begin{array}{l}\text { Kemeny } \\
\text { et al. } \\
2005 \\
{[46]}\end{array}$ & $\begin{array}{l}\text { Pro, } \\
\text { phase I }\end{array}$ & $\begin{array}{l}\text { Arm1: HAIC } \rightarrow \text { FUDR + DEXA } \\
\text { IV } \rightarrow \text { oxaliplatin }+ \text { CPT-11 } \\
\text { Arm2: HAIC } \rightarrow \text { FUDR + DEXA } \\
\text { IV } \rightarrow \text { oxaliplatin }+5-\text { FU + LV }\end{array}$ & $\begin{array}{l}\text { First } \\
\text { line: } 4 \\
\text { After } \\
\text { first line: } \\
32\end{array}$ & $\begin{array}{l}\text { Unresectable } \\
\text { liver confined }\end{array}$ & $36(36)$ & $\begin{array}{l}36 \\
22\end{array}$ & $\begin{array}{l}90 \% \\
87 \%\end{array}$ & \\
\hline $\begin{array}{l}\text { Kemeny } \\
\text { et al. } \\
2009 \\
{[31]}\end{array}$ & $\begin{array}{l}\text { Pro, } \\
\text { phase I }\end{array}$ & $\begin{array}{l}\text { HAIC } \rightarrow \text { FUDR + Dexa } \\
\text { IV } \rightarrow \text { Oxaliplatin + CPT-11 }\end{array}$ & $\begin{array}{l}\text { First } \\
\text { line: } 23 \\
\text { Second } \\
\text { line: } 26\end{array}$ & $\begin{array}{l}\text { Unresectable } \\
\text { liver confined }\end{array}$ & 49 (49) & $\begin{array}{l}\text { First line: } \\
50.8 \\
\text { Second } \\
\text { line: } 35\end{array}$ & $92 \%$ & RCR: $47 \%$ \\
\hline $\begin{array}{l}\text { Kemeny } \\
\text { et al. } \\
2005 \\
{[47]}\end{array}$ & $\begin{array}{l}\text { Pro, } \\
\text { phase II }\end{array}$ & HAIC $\rightarrow$ FUDR + Dexa + Mit-C & $\begin{array}{l}\text { First } \\
\text { line: } 26 \\
\text { Second } \\
\text { line: } 37\end{array}$ & $\begin{array}{l}\text { Unresectable } \\
\text { liver confined }\end{array}$ & $63(63)$ & $\begin{array}{c}\text { First line: } \\
23 \\
\text { Second } \\
\text { line: } 20\end{array}$ & $\begin{array}{l}\text { First } \\
\text { line: } \\
73 \% \\
\text { Sec- } \\
\text { ond } \\
\text { line: } \\
70 \%\end{array}$ & \\
\hline $\begin{array}{l}\text { Lorenz } \\
\text { et al. } \\
2001 \\
{[48]} \\
\end{array}$ & $\begin{array}{l}\text { Pro, } \\
\text { phase II }\end{array}$ & $\mathrm{HAIC} \rightarrow 5-\mathrm{FU}+\mathrm{LV}$ & $\begin{array}{l}\text { First } \\
\text { line: } 40 \\
\text { Second } \\
\text { line: } 10 \\
\end{array}$ & $\begin{array}{l}\text { Unresectable } \\
\text { liver confined }\end{array}$ & $50(50)$ & 22.3 & $56 \%$ & \\
\hline
\end{tabular}


TABLE 2: Continued.

\begin{tabular}{|c|c|c|c|c|c|c|c|c|}
\hline $\begin{array}{l}\text { Authors/ } \\
\text { Year }\end{array}$ & Setting & Treatment & Line & $\begin{array}{l}\text { Inclusion } \\
\text { population }\end{array}$ & $\begin{array}{l}\text { Patient no. } \\
{\text { (treat })^{\mathrm{a}}}\end{array}$ & $\begin{array}{l}\text { Median } \\
\text { OS } \\
\text { (months) }\end{array}$ & $\mathrm{RR}$ & Note \\
\hline $\begin{array}{l}\text { Boige } \\
\text { et al. } \\
2008 \\
{[38]}\end{array}$ & Pro & $\begin{array}{l}\text { HAIC } \rightarrow \text { oxaliplatin } \\
\mathrm{IV} \rightarrow 5-\mathrm{FU}+\mathrm{LV}\end{array}$ & $\begin{array}{l}\text { After } \\
\text { first line }\end{array}$ & $\begin{array}{l}\text { Unresectable } \\
\text { liver confined }\end{array}$ & $44(43)$ & 16 & $62 \%$ & RCR: $18 \%$ \\
\hline $\begin{array}{l}\text { Fazio } \\
\text { et al. } \\
2003 \\
{[49]} \\
\end{array}$ & Ret & HAIC $\rightarrow$ cisplatin + Mit-C + 5-FU & $\begin{array}{l}\text { After } \\
\text { first line }\end{array}$ & $\begin{array}{l}\text { Hepatic mets } \\
\text { predominent }^{c}\end{array}$ & $45(44)$ & NM & $35 \%$ & \\
\hline $\begin{array}{l}\text { Kemeny } \\
\text { et al. } \\
2001 \\
{[50]}\end{array}$ & $\begin{array}{l}\text { Pro, } \\
\text { phase I }\end{array}$ & $\begin{array}{c}\mathrm{HAIC} \rightarrow \text { FUDR + DEXA } \\
\text { IV } \rightarrow \text { CPT-11 }\end{array}$ & $\begin{array}{l}\text { After } \\
\text { first line }\end{array}$ & $\begin{array}{l}\text { Unresectable } \\
\text { liver confined }\end{array}$ & $46(46)$ & 17.2 & $74 \%$ & \\
\hline $\begin{array}{l}\text { Van Riel } \\
\text { et al. } \\
2000 \\
{[51]}\end{array}$ & Ret & $\mathrm{HAIC} \rightarrow 5-\mathrm{FU}$ & All & $\begin{array}{l}\text { Hepatic mets } \\
\text { predominent }^{c}\end{array}$ & 145 (145) & $14.3 \mathrm{~m}$ & $34 \%$ & $\begin{array}{c}\text { Hepatic } \\
\text { artery } \\
\text { thrombosis } \\
(48 \%) \\
\end{array}$ \\
\hline $\begin{array}{l}\text { Fujimoto } \\
\text { et al. } \\
2009 \\
\text { [52] }\end{array}$ & Ret & $\mathrm{HAIC} \rightarrow 5-\mathrm{FU}$ & NM & $\begin{array}{l}\text { Unresectable } \\
\text { liver confined }\end{array}$ & $72(72)$ & 18 & $38 \%$ & \\
\hline $\begin{array}{l}\text { Sameshima } \\
\text { et al. } \\
2007 \\
{[53]}\end{array}$ & Ret & $\mathrm{HAIC} \rightarrow 5$-FU & NM & $\begin{array}{l}\text { Unresectable } \\
\text { liver confined }\end{array}$ & $42(42)$ & 29.1 & $57 \%$ & \\
\hline \multicolumn{9}{|c|}{$\begin{array}{l}\text { Selected studies that enroll patients with colorectal cancer-related liver-confined metastatic disease are listed here. Studies designed for patients with colorectal } \\
\text { cancer to receive systemic chemotherapy in combination with HAIC are listed in Table } 1 . \\
{ }^{*} \text { With statistical significance. } \\
\text { 'Actual patients' number who received treatment. } \\
\text { b Patients who did not receive treatment in arm1 and arm3 received treatment as arm2. } \\
{ }^{c} \text { Trial enrolled patients with liver-confined disease or "minimal" extrahepatic disease. } \\
\text { Abbreviations-OS: overall survival, RR: response rate, Pro: prospective, Ran: randomized, Ret: retrospective, NM: not mentioned, HAIC: hepatic artery } \\
\text { infusion chemotherapy, IV: intravenous, FUDR: floxuridine, LV: leucovorin, Dexa: dexamethasone, Mit-C: mitomycin C, CPT-11: irinotecan, QOL: quality of } \\
\text { life, Mets: metastasis, and RCR: resectability conversion rate. }\end{array}$} \\
\hline
\end{tabular}

The RR was 73\% in the chemotherapy-naive patients and 70\% in previously-treated patients. However, the expense was a high biliary toxicity. Elevation of the serum bilirubin level $>3 \mathrm{mg} / \mathrm{dL}$ occurred in $22.5 \%$ patients. Half of the patients suffered from at least a doubling of the serum hepatic transaminase level. Besides, biliary sclerosis was noted in 6 patients (9.5\%) and liver bilomas in 5 (7.9\%) patients.

Fallik et al. enrolled 75 patients with CRC and inoperable liver-confined metastatic diseases in a phase II trial [11]. All patients received intravenous 5 -FU and $\mathrm{LV}$ in combination with HAIC using pirarubicin, an anthracycline analog. The overall RR was $31.9 \%$ and the median OS was 19 months. Most important was that grade 4 neutropenia was reported for 27 cycles $(23 \%)$. The toxicity profile seemed acceptable in this trial and no cardiac toxicity was reported.

Several small studies in the literature have addressed the use of HAIC in liver-confined disease of CRC. The study designs and results were heterogeneous across these trials. Therefore, Mocellin et al. conducted a meta-analysis to compare HAIC and intravenous chemotherapy for liverconfined metastatic diseases of CRC $[54,55]$. Ten randomized controlled trials, including a total of 1277 patients, were enrolled in the analysis. All studies used 5-FU or FUDR as single agents via HAIC or intravenous chemotherapy. Although the RR was significantly higher in patients receiving HAIC than in patients receiving intravenous chemotherapy ( $42.9 \%$ versus $18.4 \%, P<0.001$ ), the median OS was not significantly longer (15.9 months versus 12.4 months, $P=$ 0.240).

The result of this meta-analysis should be interpreted cautiously. The analyzed ten clinical trials were mostly conducted a decade ago and used 5-FU only in intravenous chemotherapy, which is clearly inadequate as compared with present therapies. This explains the inferior OS outcome of 12 months only in either treatment arm and the uncertainty regarding the interpretation of this meta-analysis result. On the contrary, many patients who were allocated into the HAIC arms in these trials did not receive HAIC mainly due to catheter-related complications. Some of them were allowed to cross over into intravenous chemotherapy arms but still analyzed as HAIC in an intent-to-treat manner. All these reasons suggest difficulty in interpretation of this meta-analysis. 
According to current evidence, HAIC demonstrates better locoregional control for CRC patents with liver-confined disease, at the expense of poor extrahepatic disease progression. Although there was a survival benefit for HAIC-treated patients reported in the CALGB 9481 study, this OS benefit became nonsignificant when ten studies were enrolled into a meta-analysis. Evidence as to whether HAIC provides a better survival benefit than systemic therapy is thus still lacking, and further large-scale clinical trials are warranted. Except for 5-FU and FUDR, some other cytotoxic agents such as Mit$\mathrm{C}$ and pirarubicin are also applied via HAIC. As we know, anthracycline drugs were thought to be ineffective in the treatment of CRC. However, anthracycline analogs demonstrated potential efficacy in CRC via HAIC because of their special mechanism, which provides a greater drug selection for the treatment of CRC.

2.4. HAIC after Curative Hepatectomy. With improvement in surgical techniques, more and more CRC patients with liverconfined metastasis receive surgery for both the primary CRC and liver tumors with a curative intent. Prevention of disease recurrence is crucial in these patients. Some physicians use a local treatment, HAIC, in this adjuvant setting.

Kemeny et al. enrolled 156 CRC patients who received complete resection of liver metastatic disease [56, 57]. These patients were randomized into groups receiving either intravenous 5-FU alone or in combination with HAIC using FUDR. In an updated result after a median follow-up duration of 10.3 years, patients who received combination therapy with HAIC had a significantly longer progression-free survival than patients who received intravenous therapy alone (31.3 months versus 17.2 months, $P=0.02$ ) [57]. Although the OS was not significantly different, the trend still favored combination therapy with HAIC (68.4 months versus 58.8 months, $P=0.10$ ).

Oxaliplatin is the current standard for adjuvant treatment of stage III CRC [58]. When the efficacy of newer agents for the treatment of CRC has been proven, they have been tested for HAIC. Alberts et al. conducted a phase II trial that enrolled 76 patients with CRC who had liver-confined metastasis [59]. After curative surgery for both the primary tumor and liver metastases, patients received adjuvant intra-venous oxaliplatin and oral capecitabine alternated with HAIC FUDR plus dexamethasone. Although 3 treatment-related deaths were reported, the median disease-free survival was 32.7 months and only 30 patients developed recurrent malignancies after median follow-up time of 4.8 years.

In addition to oxaliplatin, CPT-11 has also shown a fair efficacy for stage $4 \mathrm{CRC}$ and thus was also examined in combination with HAIC. Kemeny et al. conducted a phase I/II trial that enrolled 96 patients with CRC who had liverconfined metastasis [60]. After curative surgery, patients received adjuvant intravenous $\mathrm{CPT}-11$ combined with HAIC FUDR plus dexamethasone. With a median follow-up time of 26 months, the 2 -year survival rate was $89 \%$, and 1.5 -year hepatic disease-free survival rate was $88 \%$.

In the targeted therapy era, a combination of HAIC with novel targeted agents was also tested in some series. Kemeny et al. randomly assigned $73 \mathrm{CRC}$ patients with resected liverconfined disease to receive curative hepatectomy [61]. All patients received intravenous oxaliplatin or CPT-11 plus infusional 5-FU in combination with FUDR plus dexamethasone via HAIC. Patients were randomized into two arms, receiving intravenous bevacizumab or not. The 4 -year recurrence-free survival rate was $46 \%$ and $37 \%$ for the no bevacizumab arm and the bevacizumab arm $(P=0.4)$, respectively, after a median follow-up duration of 30 months.

There have recently been some convincing results showing a lower recurrence rate for HAIC in combination with systemic therapy after curative hepatectomy. Systemic chemotherapy after curative surgery for liver metastatic disease is still the standard treatment, and HAIC might provide enhanced locoregional control for the liver. Further large-scale phase III trials are warranted.

\section{Other Malignancies}

3.1. Gastric Cancer. The prognosis of gastric cancer with liver metastases is extremely poor, with median OS of only 2-6 months if untreated [62]. The standard treatment is combination systemic chemotherapy including platinum analogs and 5-FU. For better palliation, some case series reported the efficacy of HAIC as a liver-directed therapy. Tarazov reported the results of HAIC using 5-FU and doxorubicin in 12 patients with unresectable gastric cancer-related bilobar liver metastases [62]. The RR was $25 \%$ and the median OS was 23 months. One patient had 60 months of stable disease after 7 courses of HAIC treatment. Kumada et al. conducted a phase II trial that tested HAIC with 5-FU, epirubicin, and Mit-C in 63 patients with gastric cancer who had unresectable liver metastasis [63]. Only 36 patients were documented to have liver-confined metastatic diseases. The response rate was $55.6 \%$, with three complete responders. For patients with liver-confined disease, the median OS was 13 months.

As a treatment for synchronous multiple liver metastases from gastric cancer after palliative gastrectomy to maintain quality of life, Ojima et al. retrospectively analyzed 18 patients who received HAIC with 5-FU [64]. The RR was $83 \%$ with a response duration of 7.6 months. The median OS was 19.2 months.

According to the limited data above, HAIC potentially provides high response rates in patients with liver metastases of gastric cancer. The median OS in these small groups of patients seemed longer given that the best survival in patients receiving systemic chemotherapy has been reported to be 13.8 months [65]. Therefore, HAIC might have the potential to be a feasible local treatment for gastric cancer with unresectable liver metastases.

3.2. Uveal Melanoma. Uveal melanoma usually hematogenously spreads into the liver in up to $95 \%$ patients [66]. Once liver metastases occur, the life expectancy is less than 5 months. Because no systemic therapy is proved to have definite efficacy for metastatic uveal melanoma, regional therapy to control liver metastases and delay extrahepatic spread 
becomes one of the treatment choices. Melichar et al. performed HAIC with the combination of cisplatin, vinblastine, and dacarbazine in 10 liver metastatic uveal melanoma patients [67]. Two patients had partial response, and four patients achieved stable disease. Those who had clinical benefit survived for more than one year. Becker et al. conducted a phase II prospective clinical trial that enrolled 48 patients with metastatic uveal melanoma [66]. HAIC with fotemustine was given to the 23 patients who had liver metastases alone. Intravenous fotemustine was given to the 25 patients who had metastases other than liver. All patients received subcutaneous interleukin-2 and interferon $\alpha$. The overall RR was significantly higher for patients who received HAIC than those patients who received intravenous chemotherapy (21.7\% versus $8.0 \%)$. However, the median OS was similar (369 days versus 349 days).

With the therapeutic activity demonstrated above, HAIC might play a role to control liver-confined metastatic uveal melanoma. Comparing with the cumulating results from chemoembolization in uveal melanoma with liver metastases, the evidence for the better efficacy of HAIC is still scarce and needs more studies [68].

3.3. Pancreatic Cancer. The prognosis of pancreatic cancer is extremely poor because of the low resection rate at diagnosis, rapid progression, and frequent metastasis even after curative surgery. Despite the advances of cancer therapy generally, the survival of patients with pancreatic cancer did not improve significantly in the past decades. Liver is the most common site of metastasis, and thus, HAIC was examined as a strategy for palliation or prevention of liver metastasis. For unresectable pancreatic cancer without metastasis, HAIC was also examined as a primary treatment modality for primary tumors from pancreatic body and tails [69].

Homma et al. also enrolled 16 patients with pancreatic cancer-related liver metastases who received cisplatin and 5FU via HAIC [70]. The RR was $68.8 \%$ with median survival 16.25 months.

There were few studies focusing on HAIC in the adjuvant setting. Hashimoto et al. conducted a retrospective analysis that enrolled 42 patients with pancreatic cancer who received curative pancreatectomy and subsequent 5-FU via HAIC [71]. Hepatic recurrence rate was $7.1 \%$ with a median 19 -month followup.

From the above studies, HAIC for pancreatic cancer is a way for local treatment. Besides, HAIC also provides potential benefit to reduce recurrence after pancreatectomy, compared to the $36 \%$ recurrent rate reported by CONKO-001 study using systemic gemcitabine alone [72]. The cost of relative high complication rate remains the problem. Common complications include high probability of hepatic arterial stenosis (19.6\%) and liver abscess (3.6\%). Due to the limitation of various HAIC techniques and different vasculatures of each patient, large prospective trial is required for further investigation.

3.4. Biliary Tree Cancer. Due to limited effective therapy for unresectable and metastatic biliary tract cancers, HAIC was also applied in several studies. These studies of biliary tract cancer were heterogeneous in patient population, and most studies included more than one cancer type. Inaba et al. conducted a phase I/II trial for patients with unresectable intrahepatic cholangiocarcinoma [73]. HAIC with gemcitabine was applied in 13 patients. One patient had partial response and 8 patients had stable disease. The response rate was $7.7 \%$. In addition to gemcitabine, cisplatin and epirubicin combination were also examined. Cantore et al. conducted a phase II study that enrolled 25 patients with metastatic intrahepatic cholangiocarcinoma and 5 patients with gallbladder carcinoma to receive intravenous 5-FU and HAIC with cisplatin and epirubicin [74]. Overall RR was $40 \%$ including 1 patient who achieved complete remission. Median OS was 13.2 months. Mambrini et al. conducted a phase II trial that enrolled 20 patients with unresectable metastatic intra- or extra-hepatic biliary tree cancers to receive oral capecitabine and HAIC using cisplatin and epirubicin [75]. The overall RR was $31.5 \%$, and median OS was 18 months.

From the evidence of these phase II studies, combination HAIC with oral or intravenous chemotherapy seems to be a safe and effective treatment modality. With the advance of intervention radiology and radiotherapy techniques, multimodality treatment incorporating radiation, drug-eluting beads, and chemoembolization were also developing in combination with HAIC $[76,77]$. Further comparison of different treatments modality and large scale phase III trials are needed.

3.5. Neuroendocrine Tumor. Gastroenteropancreatic neuroendocrine tumors often metastasize to liver and contribute substantially to one of the most important noncolorectal causes of liver metastases [78]. Due to limited patients numbers, HAIC for unresectable liver metastases from neuroendocrine tumors has mostly been studied retrospectively.

Christante et al. collected 77 patients with extensive liver metastases with disease progression after octreotide treatment [79]. Fifty-nine patients received four cycles of 5-FU via HAIC with the addition of selective chemoembolization at the end of third and fourth cycles. However, 18 patients received HAIC alone due to the concern of hepatotoxicity. Overall response rate was $80 \%$, and median progression-free survival was 19 months, and all the responders were treated with combination of HAIC and chemoembolization.

Most of the HAIC studies in neuroendocrine tumors were conducted in combination with chemoembolization. Due to the limitation of scarce retrospective studies with HAIC treatment alone, the efficacy of HAIC for neuroendocrine tumors seems to be difficult to clearly be identified based on current evidences. Further studies are warranted.

\section{Conclusion}

In this article, we presented the current lines of evidence of HAIC as a treatment of liver metastases. HAIC provides a good locoregional control to liver tumors. Most of evidences mainly came from studies of CRC. For patients with CRC and inoperable liver metastasis, HAIC has potentials to 
enhance the treatment response of the liver metastases when combined with systemic chemotherapy. For CRC patients who had failed previous intravenous chemotherapies, HAIC still provides fair efficacy of control to liver tumors. Patients with initially considered inoperable liver metastases could have a chance to receive surgery if HAIC converts the tumors back to operable status. However, the evidence to support if HAIC could totally replace the intravenous chemotherapies is still not strong enough across previous trials. Therefore, current standard for liver metastatic CRC is still intravenous chemotherapy, and HAIC could be provided as local control focusing on liver. As for CRC patients with initially operable liver metastatic tumors who received curative operation, HAIC in combination with intravenous chemotherapies demonstrated good competence to reduce liver recurrent and to subsequently prolong the overall survival. Some new agents could be used in HAIC in combination to systemic agents, such as pirarubicin, which is initially considered ineffective for CRC. With the emergent novel agents and targeted agents in the 21 century, more studies are needed for different combinations with HAIC.

HAIC is also applied for other malignant diseases with liver metastases, especially for those malignancies which have poor response to systemic chemotherapy, such as melanoma or pancreatic cancer. Although the results for large-scale prospective phase III trials are warranted, HAIC seems to become an attractive procedure for hepatic metastatic diseases in the future.

\section{Abbreviations}

CRC: Colorectal cancer

HAIC: Hepatic artery infusion chemotherapy

OS: Overall survival

5-FU: 5-Fluorouracil

FUDR: Floxuridine

RR: Response rate

CPT-11: Irinotecan

LV: Leucovorin

TACE: Transarterial chemoembolization

MIT-C: Mitomycin C

IV: Intravenous

GI: Gastrointestinal.

\section{Acknowledgment}

This study was supported by a Grant from the National Science Council in Taiwan (NSC 101-2314-B-002-164).

\section{References}

[1] J. P. Ayoub, K. R. Hess, M. C. Abbruzzese, R. Lenzi, M. N. Raber, and J. L. Abbruzzese, "Unknown primary tumors metastatic to liver," Journal of Clinical Oncology, vol. 16, no. 6, pp. 2105-2112, 1998.

[2] S. Manfredi, C. Lepage, C. Hatem, O. Coatmeur, J. Faivre, and A. M. Bouvier, "Epidemiology and management of liver metastases from colorectal cancer," Annals of Surgery, vol. 244, no. 2, pp. 254-259, 2006.
[3] J. S. Tomlinson, W. R. Jarnagin, R. P. DeMatteo et al., "Actual 10 -year survival after resection of colorectal liver metastases defines cure," Journal of Clinical Oncology, vol. 25, no. 29, pp. 4575-4580, 2007.

[4] T. Ruers and R. P. Bleichrodt, "Treatment of liver metastases, an update on the possibilities and results," European Journal of Cancer, vol. 38, no. 7, pp. 1023-1033, 2002.

[5] R. Stangl, A. Altendorf-Hofmann, R. M. Charnley, and J. Scheele, "Factors influencing the natural history of colorectal liver metastases," Lancet, vol. 343, no. 8910, pp. 1405-1410, 1994.

[6] J. A. Ridge, J. R. Bading, and A. S. Gelbard, "Perfusion of colorectal hepatic metastases. Relative distribution of flow from the hepatic artery and portal vein," Cancer, vol. 59, no. 9, pp. 15471553, 1987.

[7] N. B. Ackerman, "Experimental studies on the circulation dynamics of intrahepatic tumor blood supply," Cancer, vol. 29, no. 2, pp. 435-439, 1972.

[8] W. D. Ensminger, A. Rosowsky, and V. Raso, "A clinical-pharmacological evaluation of hepatic arterial infusions of 5-fluoro2 ' deoxyuridine and 5-fluorouracil," Cancer Research, vol. 38, no. 11, pp. 3784-3792, 1978.

[9] J. N. Munck, P. Rougier, G. G. Chabot et al., "Phase I and pharmacological study of intraarterial hepatic administration of pirarubicin in patients with advanced hepatic metastases," European Journal of Cancer A, vol. 30, no. 3, pp. 289-293, 1994.

[10] P. Rougier, J. N. Munck, D. Elias et al., "Intra-arterial hepatic chemotherapy with pirarubicin. Preclinical and clinical studies," American Journal of Clinical Oncology, vol. 13, supplement 1, pp. S1-S4, 1990.

[11] D. Fallik, M. Ychou, J. Jacob et al., "Hepatic arterial infusion using pirarubicin combined with systemic chemotherapy: a phase II study in patients with nonresectable liver metastases from colorectal cancer," Annals of Oncology, vol. 14, no. 6, pp. 856-863, 2003.

[12] N. Hayashi, T. Sakai, M. Kitagawa, T. Kimoto, and Y. Ishii, "Percutaneous long-term arterial access with implantable ports direct subclavian approach with US," European Journal of Radiology, vol. 26, no. 3, pp. 304-308, 1998.

[13] M. Yoshikawa, M. Ebara, T. Nakano, A. Minoyama, N. Sugiura, and M. Ohto, "Percutaneous transaxillary catheter insertion for hepatic artery infusion chemotherapy," American Journal of Roentgenology, vol. 158, no. 4, pp. 885-886, 1992.

[14] R. M. Barone, J. E. Byfield, and P. B. Goldfarb, "Intra-arterial chemotherapy using an implantable infusion pump and liver irradiation for the treatment of hepatic metastases," Cancer, vol. 50, no. 5, pp. 850-862, 1982.

[15] H. Buchwald, T. B. Grage, and P. P. Vassilopoulos, "Intraarterial infusion chemotherapy for hepatic carcinoma using a totally implantable infusion pump," Cancer, vol. 45, no. 5, pp. 866-869, 1980.

[16] P. J. Allen, A. Nissan, A. I. Picon et al., “Technical complications and durability of hepatic artery infusion pumps for unresectable colorectal liver metastases: an institutional experience of 544 consecutive cases," Journal of the American College of Surgeons, vol. 201, no. 1, pp. 57-65, 2005.

[17] K. T. Barnett and M. P. Malafa, "Complications of hepatic artery infusion: a review of 4580 reported cases," International Journal of Gastrointestinal Cancer, vol. 30, no. 3, pp. 147-160, 2001.

[18] Y. Arai, Y. Inaba, Y. Takeuchi, and Y. Ariyoshi, "Intermittent hepatic arterial infusion of high-dose 5FU on a weekly schedule for liver metastases from colorectal cancer," Cancer Chemotherapy and Pharmacology, vol. 40, no. 6, pp. 526-530, 1997. 
[19] O. Kanat, A. Gewirtz, and N. Kemeny, "What is the potential role of hepatic arterial infusion chemo-therapy in the current armamentorium against colorectal cancer," Journal of Gastrointestinal Oncology, vol. 3, pp. 130-138, 2012.

[20] Y. Y. Shao, C. C. Huang, P. C. Liang, and Z. Z. Lin, "Hepatic arterial infusion of chemotherapy for advanced hepatocellular carcinoma," Asia-Pacific Journal of Clinical Oncology, vol. 6, no. 2, pp. 80-88, 2010.

[21] A. D. Cohen and N. E. Kemeny, "An update on hepatic arterial infusion chemotherapy for colorectal cancer," Oncologist, vol. 8, no. 6, pp. 553-566, 2003.

[22] H. Toyoda, S. Nakano, T. Kumada et al., "The efficacy of continuous local arterial infusion of 5-fluorouracil and cisplatin through an implanted reservoir for severe advanced hepatocellular carcinoma," Oncology, vol. 52, no. 4, pp. 295-299, 1995.

[23] A. Minoyama, M. Yoshikawa, M. Ebara, H. Saisho, N. Sugiura, and M. Ohto, "Study of repeated arterial infusion chemotherapy with a subcutaneously implanted reservoir for advanced hepatocellular carcinoma," Journal of Gastroenterology, vol. 30, no. 3, pp. 356-366, 1995.

[24] A. Jemal, M. M. Center, C. DeSantis, and E. M. Ward, "Global patterns of cancer incidence and mortality rates and trends," Cancer Epidemiology Biomarkers and Prevention, vol. 19, no. 8, pp. 1893-1907, 2010.

[25] J. Ferlay, H. R. Shin, F. Bray, D. Forman, C. Mathers, and D. M. Parkin, "Estimates of worldwide burden of cancer in 2008: GLOBOCAN 2008," International Journal of Cancer, vol. 127, no. 12, pp. 2893-2917, 2010.

[26] T. Yamaguchi, H. Matsumoto, M. Yasutome, T. Mori, and K. Takahashi, "Phase I/II study of irinotecan, UFT and leucovorin with hepatic arterial infusion using 5-FU in colorectal cancer patients with unresectable liver metastases," Cancer Chemotherapy and Pharmacology, vol. 67, no. 3, pp. 629-635, 2011.

[27] R. Mancini, M. Tedesco, C. Garufi et al., "Hepatic arterial infusion (HAI) of cisplatin and systemic fluorouracil in the treatment of unresectable colorectal liver metastases," Anticancer Research C, vol. 23, no. 2, pp. 1837-1841, 2003.

[28] D. Goéré, I. Deshaies, T. De Baere et al., "Prolonged survival of initially unresectable hepatic colorectal cancer patients treated with hepatic arterial infusion of oxaliplatin followed by radical surgery of metastases," Annals of Surgery, vol. 251, no. 4, pp. 686-691, 2010.

[29] D. J. Gallagher, M. Capanu, G. Raggio, and N. Kemeny, "Hepatic arterial infusion plus systemic irinotecan in patients with unresectable hepatic metastases from colorectal cancer previously treated with systemic oxaliplatin: a retrospective analysis," Annals of Oncology, vol. 18, no. 12, pp. 1995-1999, 2007.

[30] P. Pilati, E. Mammano, S. Mocellin, E. Tessari, M. Lise, and D. Nitti, "Hepatic arterial infusion for unresectable colorectal liver metastases combined or not with systemic chemotherapy," Anticancer Research, vol. 29, no. 10, pp. 4139-4144, 2009.

[31] N. E. Kemeny, F. D. Huitzil Melendez, M. Capanu et al., "Conversion to resectability using hepatic artery infusion plus systemic chemotherapy for the treatment of unresectable liver metastases from colorectal carcinoma," Journal of Clinical Oncology, vol. 27, no. 21, pp. 3465-3471, 2009.

[32] C. Bokemeyer, I. Bondarenko, J. T. Hartmann et al., "Efficacy according to biomarker status of cetuximab plus FOLFOX-4 as first-line treatment for metastatic colorectal cancer: the OPUS study," Annals of Oncology, vol. 22, no. 7, pp. 1535-1546, 2011.

[33] T. S. Maughan, R. A. Adams, C. G. Smith et al., "Addition of cetuximab to oxaliplatin-based first-line combination chemotherapy for treatment of advanced colorectal cancer: results of the randomised phase 3 MRC COIN trial," The Lancet, vol. 377, no. 9783, pp. 2103-2114, 2011.

[34] K. M. Tveit, T. Guren, B. Glimelius et al., "Phase III trial of cetuximab with continuous or intermittent fluorouracil, leucovorin, and oxaliplatin (Nordic FLOX) versus FLOX alone in firstline treatment of metastatic colorectal cancer: the NORDIC-VII study," Journal of Clinical Oncology, vol. 30, pp. 1755-1762, 2012.

[35] E. Van Cutsem, C. H. Köhne, I. Láng et al., "Cetuximab plus irinotecan, fluorouracil, and leucovorin as first-line treatment for metastatic colorectal cancer: updated analysis of overall survival according to tumor KRAS and BRAF mutation status," Journal of Clinical Oncology, vol. 29, no. 15, pp. 2011-2019, 2011.

[36] M. Bouchahda, R. Adam, S. Giacchetti et al., "Rescue chemotherapy using multidrug chronomodulated hepatic arterial infusion for patients with heavily pretreated metastatic colorectal cancer," Cancer, vol. 115, no. 21, pp. 4990-4999, 2009.

[37] M. Ducreux, M. Ychou, A. Laplanche et al., "Hepatic arterial oxaliplatin infusion plus intravenous chemotherapy in colorectal cancer with inoperable hepatic metastases: a trial of the Gastrointestinal Group of the Fédération Nationale des Centres de Lutte Contre le Cancer," Journal of Clinical Oncology, vol. 23, no. 22, pp. 4881-4887, 2005.

[38] V. Boige, D. Malka, D. Elias et al., "Hepatic arterial infusion of oxaliplatin and intravenous LV5FU2 in unresectable liver metastases from colorectal cancer after systemic chemotherapy failure," Annals of Surgical Oncology, vol. 15, no. 1, pp. 219-226, 2008.

[39] L. B. Saltz, S. Clarke, E. Díaz-Rubio et al., "Bevacizumab in combination with oxaliplatin-based chemotherapy as first-line therapy in metastatic colorectal cancer: a randomized phase III study," Journal of Clinical Oncology, vol. 26, no. 18, pp. 20132019, 2008

[40] G. Folprecht, T. Gruenberger, W. O. Bechstein et al., "Tumour response and secondary resectability of colorectal liver metastases following neoadjuvant chemotherapy with cetuximab: the CELIM randomised phase 2 trial," The Lancet Oncology, vol. 11, no. 1 , pp. 38-47, 2010.

[41] N. E. Kemeny, D. Niedzwiecki, D. R. Hollis et al., "Hepatic arterial infusion versus systemic therapy for hepatic metastases from colorectal cancer: a randomized trial of efficacy, quality of life, and molecular markers (CALGB 9481)," Journal of Clinical Oncology, vol. 24, no. 9, pp. 1395-1403, 2006.

[42] G. Fiorentini, M. Cantore, S. Rossi et al., "Hepatic arterial chemotherapy in combination with systemic chemotherapy compared with hepatic arterial chemotherapy alone for liver metastases from colorectal cancer: results of a multi-centric randomized study," In Vivo A, vol. 20, no. 6, pp. 707-710, 2006.

[43] D. J. Kerr, C. S. McArdle, J. Ledermann et al., "Intrahepatic arterial versus intravenous fluorouracil and folinic acid for colorectal cancer liver metastases: a multicentre randomised trial," Lancet, vol. 361, no. 9355, pp. 368-373, 2003.

[44] T. G. Allen-Mersh, C. Glover, C. Fordy, P. Mathur, and H. Quinn, "Randomized trial of regional plus systemic fluorinated pyrimidine compared with systemic fluorinated pyrimidine in treatment of colorectal liver metastases," European Journal of Surgical Oncology, vol. 26, no. 5, pp. 468-473, 2000.

[45] M. Lorenz and H. H. Müller, "Randomized, multicenter trial of fluorouracil plus leucovorin administered either via hepatic arterial or intravenous infusion versus fluorodeoxyuridine 
administered via hepatic arterial infusion in patients with nonresectable liver metastases from colorectal carcinoma," Journal of Clinical Oncology, vol. 18, no. 2, pp. 243-254, 2000.

[46] N. Kemeny, W. Jarnagin, P. Paty et al., "Phase I trial of systemic oxaliplatin combination chemotherapy with hepatic arterial infusion in patients with unresectable liver metastases from colorectal cancer," Journal of Clinical Oncology, vol. 23, no. 22, pp. 4888-4896, 2005.

[47] N. Kemeny, A. Eid, J. Stockman et al., "Hepatic arterial infusion of Floxuridine and dexamethasone plus high-dose Mitomycin $\mathrm{C}$ for patients with unresectable hepatic metastases from colorectal carcinoma," Journal of Surgical Oncology, vol. 91, no. 2, pp. 97-101, 2005.

[48] M. Lorenz, H. H. Mueller, E. Mattes et al., "Phase II study of weekly 24-hour intra-arterial high-dose infusion of 5-fluorouracil and folinic acid for liver metastasses from colorectal carcinomas," Annals of Oncology, vol. 12, no. 3, pp. 321-325, 2001.

[49] N. Fazio, F. Orsi, R. F. Grasso et al., "Hepatic intra-arterial chemotherapy using a percutaneous catheter in pretreated patients with metastatic colorectal carcinoma," Anticancer Research D, vol. 23, no. 6, pp. 5023-5030, 2003.

[50] N. E. Kemeny, M. Gonen, D. Sullivan et al., "Phase I study of hepatic arterial infusion of floxuridine and dexamethasone with systemic irinotecan for unresectable hepatic metastases from colorectal cancer," Journal of Clinical Oncology, vol. 19, no. 10, pp. 2687-2695, 2001.

[51] J. M. G. H. Van Riel, C. J. Van Groeningen, S. H. M. Albers et al., "Hepatic arterial 5-fluorouracil in patients with liver metastases of colorectal cancer: single-centre experience in 145 patients," Annals of Oncology, vol. 11, no. 12, pp. 1563-1570, 2000.

[52] Y. Fujimoto, T. Akasu, S. Yamamoto, S. Fujita, and Y. Moriya, "Long-term results of hepatectomy after hepatic arterial infusion chemotherapy for initially unresectable hepatic colorectal metastases," Journal of Gastrointestinal Surgery, vol. 13, no. 9, pp. 1643-1650, 2009.

[53] S. Sameshima, H. Horikoshi, K. Motegi et al., "Outcomes of hepatic artery infusion therapy for hepatic metastases from colorectal carcinoma after radiological placement of infusion catheters," European Journal of Surgical Oncology, vol. 33, no. 6, pp. 741-745, 2007.

[54] S. Mocellin, S. Pasquali, and D. Nitti, "FluoropyrimidineHAI (hepatic arterial infusion) versus systemic chemotherapy (SCT) for unresectable liver metastases from colorectal cancer," Cochrane Database of Systematic Reviews, no. 3, Article ID CD007823, 2009.

[55] S. Mocellin, P. Pilati, M. Lise, and D. Nitti, "Meta-analysis of hepatic arterial infusion for unresectable liver metastases from colorectal cancer: the end of an era?" Journal of Clinical Oncology, vol. 25, no. 35, pp. 5649-5654, 2007.

[56] N. Kemeny, Y. Huang, and A. M. Cohen, "Hepatic arterial infusion of chemotherapy after resection of hepatic metastases from colorectal cancer," New England Journal of Medicine, vol. 341, pp. 2039-2048, 1999.

[57] N. E. Kemeny and M. Gonen, "Hepatic arterial infusion after liver resection," New England Journal of Medicine, vol. 352, no. 7, pp. 734-735, 2005.

[58] T. André, C. Boni, L. Mounedji-Boudiaf et al., "Oxaliplatin, fluorouracil, and leucovorin as adjuvant treatment for colon cancer," New England Journal of Medicine, vol. 350, no. 23, pp. 2343-2351, 2004.

[59] S. R. Alberts, M. S. Roh, M. R. Mahoney et al., "Alternating systemic and hepatic artery infusion therapy for resected liver metastases from colorectal cancer: a North Central Cancer Treatment Group (NCCTG)/ National Surgical Adjuvant Breast and Bowel Project (NSABP) phase II intergroup trial, N9945/ CI-66," Journal of Clinical Oncology, vol. 28, no. 5, pp. 853-858, 2010.

[60] N. Kemeny, W. Jarnagin, M. Gonen et al., "Phase I/II study of hepatic arterial therapy with floxuridine and dexamethasone in combination with intravenous irinotecan as adjuvant treatment after resection of hepatic metastases from colorectal cancer," Journal of Clinical Oncology, vol. 21, no. 17, pp. 3303-3309, 2003.

[61] N. E. Kemeny, W. R. Jarnagin, M. Capanu et al., "Randomized phase II trial of adjuvant hepatic arterial infusion and systemic chemotherapy with or without bevacizumab in patients with resected hepatic metastases from colorectal cancer," Journal of Clinical Oncology, vol. 29, no. 7, pp. 884-889, 2011.

[62] P. G. Tarazov, "Transcatheter therapy of gastric cancer metastatic to the liver: preliminary results," Journal of Gastroenterology, vol. 35, no. 12, pp. 907-911, 2000.

[63] T. Kumada, Y. Arai, K. Itoh et al., "Phase II study of combined administration of 5-fluorouracil, epirubicin and mitomycin-C by hepatic artery infusion in patients with liver metastases of gastric cancer," Oncology, vol. 57, no. 3, pp. 216-223, 1999.

[64] H. Ojima, S. Ootake, T. Yokobori et al., "Treatment of multiple liver metastasis from gastric carcinoma," World Journal of Surgical Oncology, vol. 5, article 70, 2007.

[65] Y. J. Bang, E. Van Cutsem, and A. Feyereislova, "Trastuzumab in combination with chemotherapy versus chemotherapy alone for treatment of HER2-positive advanced gastric or gastrooesophageal junction cancer (ToGA): a phase 3, open-label, randomised controlled trial," The Lancet, vol. 376, no. 9749, pp. 687-697, 2010.

[66] J. C. Becker, P. Terheyden, E. Kämpgen et al., "Treatment of disseminated ocular melanoma with sequential fotemustine, interferon $\alpha$, and interleukin 2," British Journal of Cancer, vol. 87, no. 8, pp. 840-845, 2002.

[67] B. Melichar, Z. Voboril, M. Lojík, and A. Krajina, "Liver metastases from uveal melanoma: clinical experience of hepatic arterial infusion of cisplatin, vinblastine and dacarbazine," HepatoGastroenterology, vol. 56, no. 93, pp. 1157-1162, 2009.

[68] T. Vogl, K. Eichler, S. Zangos et al., "Preliminary experience with transarterial chemoembolization (TACE) in liver metastases of uveal malignant melanoma: local tumor control and survival," Journal of Cancer Research and Clinical Oncology, vol. 133, no. 3, pp. 177-184, 2007.

[69] G. H. Han, Z. X. Yin, X. J. Meng et al., "Prospective randomized clinical trial of two drug delivery pathway in the treatment of inoperable advanced pancreatic carcinoma," Chinese Journal of Digestive Diseases, vol. 7, no. 1, pp. 45-48, 2006.

[70] H. Homma, T. Doi, S. Mezawa et al., "A novel arterial infusion chemotherapy for the treatment of patients with advanced pancreatic carcinoma after vascular supply distribution via superselective embolization," Cancer, vol. 89, no. 2, pp. 303-313, 2000.

[71] A. Hashimoto, H. Nishiofuku, T. Tanaka et al., "Safety and optimal management of hepatic arterial infusion chemotherapy after pancreatectomy for pancreatobiliary cancer," American Journal of Roentgenology, vol. 198, pp. 923-930, 2012.

[72] H. Oettle, S. Post, P. Neuhaus et al., "Adjuvant chemotherapy with gemcitabine vs observation in patients undergoing curative-intent resection of pancreatic cancer: a randomized controlled trial," Journal of the American Medical Association, vol. 297, no. 3, pp. 267-277, 2007. 
[73] Y. Inaba, Y. Arai, H. Yamaura et al., "Phase I/II study of hepatic arterial infusion chemotherapy with gemcitabine in patients with unresectable intrahepatic cholangiocarcinoma (JIVROSG-0301)," American Journal of Clinical Oncology, vol. 34, no. 1, pp. 58-62, 2011.

[74] M. Cantore, A. Mambrini, G. Fiorentini et al., "Phase II study of hepatic intraarterial epirubicin and cisplatin, with systemic 5fluorouracil in patients with unresectable biliary tract tumors," Cancer, vol. 103, no. 7, pp. 1402-1407, 2005.

[75] A. Mambrini, A. Guglielmi, P. Pacetti et al., "Capecitabine plus hepatic intra-arterial epirubicin and cisplatin in unresectable biliary cancer: a phase II study," Anticancer Research C, vol. 27, no. 4, pp. 3009-3013, 2007.

[76] S. Matsumoto, H. Kiyosue, E. Komatsu et al., "Radiotherapy combined with transarterial infusion chemotherapy and concurrent infusion of a vasoconstrictor agent for nonresectable advanced hepatic hilar duct carcinoma," Cancer, vol. 100, no. 11, pp. 2422-2429, 2004.

[77] S. C. Schiffman, T. Metzger, G. Dubel et al., "Precision hepatic arterial irinotecan therapy in the treatment of unresectable intrahepatic cholangiocellular carcinoma: optimal tolerance and prolonged overall survival," Annals of Surgical Oncology, vol. 18, no. 2, pp. 431-438, 2011.

[78] A. Benevento, L. Boni, L. Frediani, A. Ferrari, and R. Dionigi, "Result of liver resection as treatment for metastases from noncolorectal cancer," Journal of Surgical Oncology, vol. 74, pp. 24-29, 2000.

[79] D. Christante, S. Pommier, B. Givi, and R. Pommier, "Hepatic artery chemoinfusion with chemoembolization for neuroendocrine cancer with progressive hepatic metastases despite octreotide therapy," Surgery, vol. 144, no. 6, pp. 885-894, 2008. 


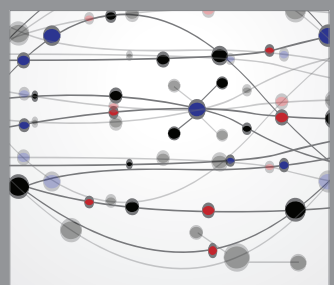

The Scientific World Journal
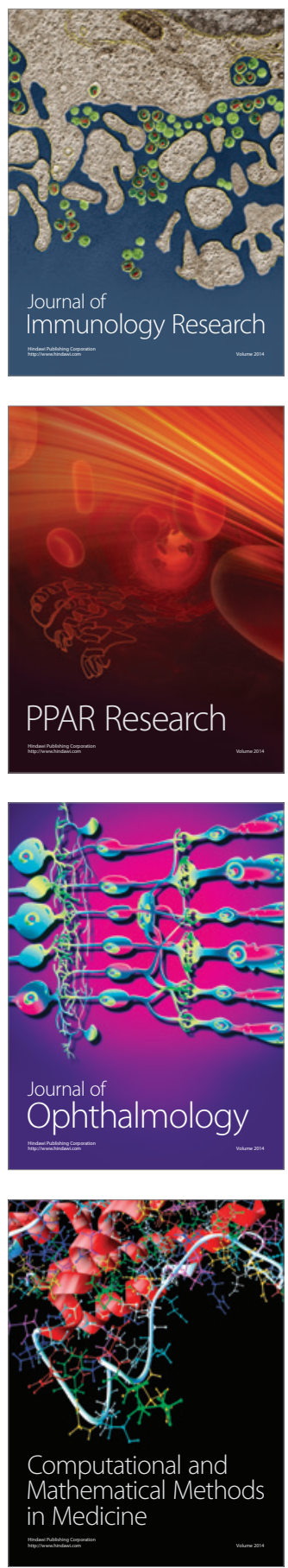

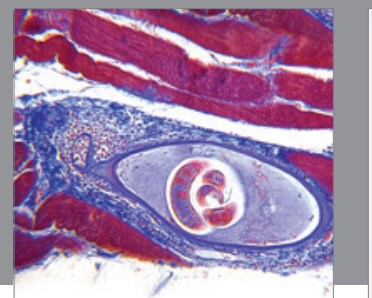

Gastroenterology

Research and Practice
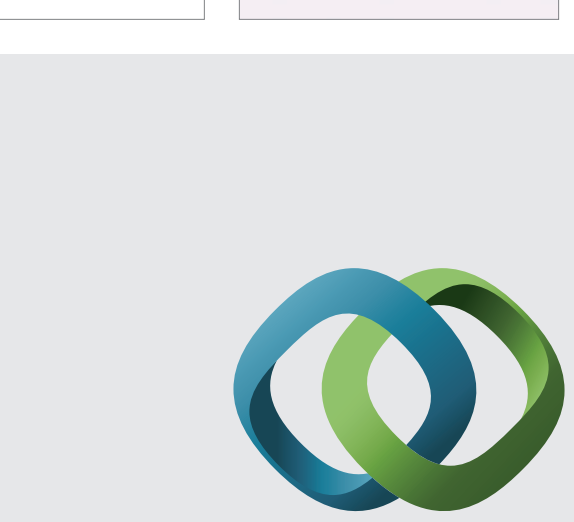

\section{Hindawi}

Submit your manuscripts at

http://www.hindawi.com
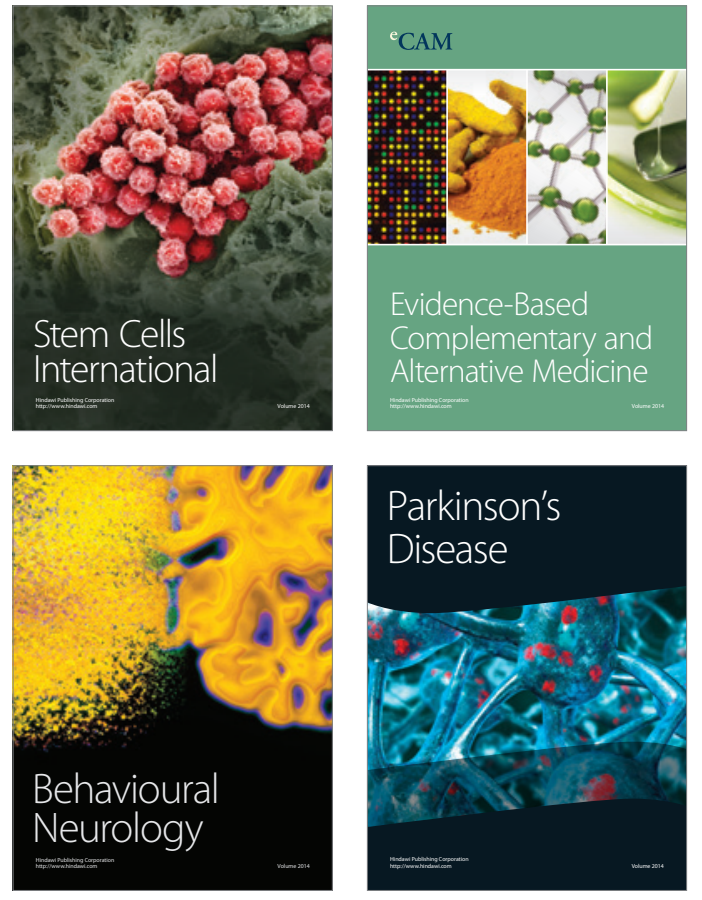
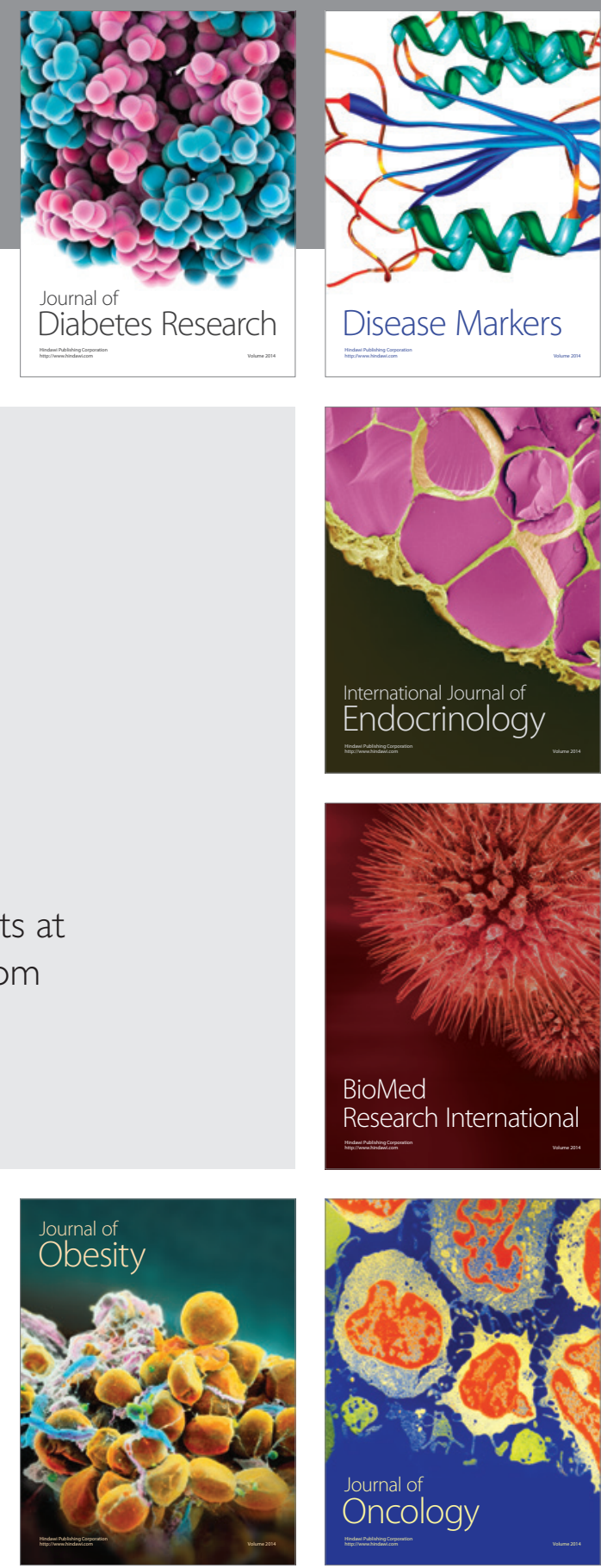

Disease Markers
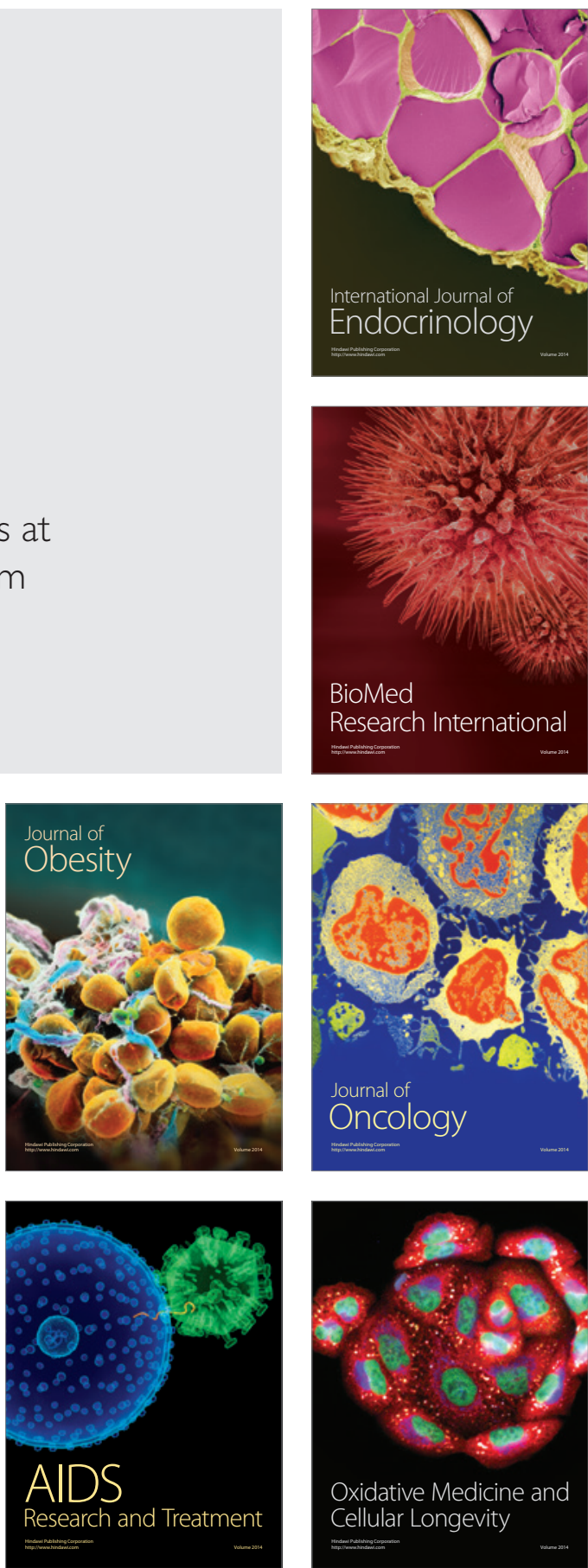